\title{
REClAMOS DE NOBLEZA EN \\ Chiapa de la Corona en 1772
}

\author{
Dolores Aramoni Calderón
}

S

abemos muy poco acerca de los caciques indios y de sus descendientes, de los pueblos coloniales de la Provincia de Chiapa. Esto se debe entre otras razones a que hasta hoy se han localizado muy pocos documentos que hagan referencia a ellos. Aquí conviene recordar que los archivos locales son pobres en manuscritos del siglo XVI, ya por los saqueos que han sufrido debido a destrucción por plagas. Algunos de los que han sido motivo de estudio son tardíos, es decir, son documentos en donde descendientes de caciques del siglo XVI solicitan certificaciones acerca de sus ascendientes con diversos fines, entre ellos, por ejemplo, la exención de tributos. Uno de los pocos trabajos relativos a este tema, Chiapas, es el publicado por Mario Ruz [1995] acerca de descendientes de caciques zoques del pueblo de Ocozocoautla.

Sin embargo, algunos caciques del siglo XVI aparecen mencionados en fuentes históricas publicadas como en las obras de fray Francisco Ximénez o fray Antonio de Remesal; en ellas se hace referencia a varios, en particular a aquellos que por haber entrado en conflicto con los encomenderos o las au-

Dolores Aramoni Calderón, Instituto de Estudios Indígenas, Universidad Autónoma de Chiapas. toridades civiles provinciales, o bien porque se aliaron con sus evangelizadores dominicos, dieron lugar a que tales disputas quedaran documentadas.

De llevarse a cabo, más y mejores estudios acerca del siglo XvI, utilizando manuscritos originales de archivos como el General de Centroamérica o el de Indias, sin duda, nos permitirían tener un mayor conocimiento sobre estos personajes de los pueblos indios y su relación con las autoridades españolas, tanto civiles como eclesiásticas.

La palabra cacique es un término cargado de fuertes significados, por ello es conveniente tratar de explicar cuál es su significado original y cómo esta palabra fue utilizada por los españoles durante la Colonia. Sin duda, el mejor estudio que se ha llevado a cabo para ciertas regiones de la Provincia de Chiapa es el de Gudrun Lenkersdorf, Repúblicas de Indios. Pueblos mayas en Chiapas. Siglo ХИ (2001). En él, la autora dedica una parte importante de la obra a explicar el uso del término cacique en la documentación colonial y a la manera confusa o arbitraria en que fue aplicado por funcionarios de diversa índole. Explica que la palabra taína cacique fue adoptada en las Antillas; originalmente, el término hacía referencia a los señores naturales, que al 
inicio de la colonización resultaban de suma importancia como intermediarios entre la población nativa y los colonizadores; sin embargo, nunca se definió con exactitud su significado, de ello resultó una aplicación arbitraria para designar a aquellos indígenas que los conquistadores reconocían como "señores" de sus pueblos. Según esta autora, la confusión se incrementó a raíz de la expedición de una cédula real de 1538, en la que se prohibía el uso del título de señor para aludir a cualquier autoridad indígena, misma cédula en la que se determina que deberán llamarse caciques o principales (Lenkersdorf 2001: 74). Esta decisión vino a hacer más difícil la comprensión de las estructuras sociopolíticas de los diversos pueblos americanos, la falta de comprensión de éste, como de otros aspectos de sus culturas de parte de los primeros españoles en América, nos dificulta seriamente el estudio de algunos rasgos culturales, en particular cuando tenemos que trabajar con documentos elaborados por los mismos españoles.

En el caso de las provincias que comprendía la Audiencia de los Confines, la confusión acerca de los caciques trató de remediarse hacia la segunda mitad del siglo XVI. La Corona trató de obtener información sobre los verdaderos caciques y ratificarles el título de tales, pero también ordenó que en aquellos poblados donde no los hubiera se designaran caciques consultando a los indios. Esto fue ordenado en virtud de que muchos conquistadores y encomenderos habían nombrado como caciques a aquellos individuos que convenían a sus intereses y no necesariamente a quienes eran "señores naturales" de sus pueblos o a quienes éstos reconocían o elegían como dignos del cargo.

El documento que presento se encuentra alojado en el Archivo Histórico Diocesano de San Cristóbal de Las Casas, Chiapas, consta de trece fojas. Para su publicación, modernicé parcialmente la or- tografía, conservé los nombres propios como aparecen en el original; entre corchetes puse palabras o fragmentos de ellas que eran ilegibles por rotura o humedad, pero que eran claramente identificables.

El expediente contiene los originales de la solicitud de don Domingo de Santa María Noti Quiñónez Guerra y Morales, cacique de Chiapa de la Real Corona, en que pide al Provisor y Vicario General del Obispado de Chiapa, en 1772, se recoja información acerca de si era natural de ese pueblo, hijo legítimo de sus padres, si sus ascendientes habían ocupado puestos honorarios en el pueblo y acerca de su vida cristiana. El expediente también contiene la información recabada en el pueblo a tres testigos indios, Vicente Balbuena (cacique, principal), Lucas de Morales y Andrés Guzmán; también incluye tres certificaciones de sacerdotes, dos de ellos dominicos: fray Francisco Montoya y fray Tomás de Loaysa y Coronado, el primero conventual y el segundo superior del convento dominico de Chiapa, y otra del presbítero Gabriel Joseph Chacón de la Peña.

Tanto los testimonios como las certificaciones son favorables al solicitante, todas ellas dejan asentado que es descendiente de caciques por vía paterna y materna, haciendo hincapié en los apellidos Morales, Quiñónez y Noti, y que muchos de sus antepasados ocuparon cargos importantes dentro del gobierno del pueblo de Chiapa, como gobernadores, alcaldes y regidores de Cabildo. Analizada la información presentada, el Provisor ordenó se extendieran a favor de don Domingo testimonios de la misma, ya que en ella quedaba probado su cacicazgo.

¿Qué motivó a don Domingo Santa María a solicitar la confirmación de su cacicazgo? En el expediente no aparece, no se hace mención explícita de sus razones; por lo que es de suponer que veía de 
algún modo afectados sus privilegios consagrados en la legislación indiana, entre ellos la exención de tributar o participar del gobierno del pueblo. La certificación del presbítero Chacón es reveladora acerca de que la segunda posibilidad le estaba negada. Chacón afirma que: "he reconocido ser un mozo de toda honra y virtud, ejercitándose a causa de sus cortas facultades en servir a eclesiásticos distinguidos, para poder alimentar, socorrer y vestir a sus ancianos padres y hermanas". Imposible saber a qué se refiere cuando menciona "sus cortas facultades", sin embargo, la frase me hace suponer que no le reconocía capacidad alguna para ejercer cargos de Cabildo. Al mismo tiempo es Chacón quien pone mayor énfasis en su relación con el cacique don Pedro Noti.

¿Por qué es importante este documento? Señalaba, al principio, que son escasos los estudios acerca de los caciques coloniales de los pueblos de la Provincia de Chiapa, y aunque este es un documento de 1772, hace referencia a uno de los caciques más nombrados del siglo XVI, don Pedro Noti.

Para referirme a este personaje utilizaré básicamente las obras de Ximénez y de Remesal, no sin señalar que para saber más acerca de él y del papel que desempeñó en los conflictos habidos entre Baltasar Guerra, encomendero de Chiapa, y los dominicos, es de importancia el estudio de los manuscritos generados en la época. Debo también dejar asentado que, en mi opinión, las aseveraciones de ambos cronistas dominicos pueden estar sesgadas o cargadas de matices a favor de don Pedro Noti, pues como se verá adelante, éste jugó un importante papel como aliado de los predicadores de Santo Domingo llegados a la Provincia de Chiapa en 1545; por ello, ambos cronistas le conceden especial importancia a sus acciones y a sus dichos.

La liga de don Domingo Santa María con el cacique don Pedro Noti es por la línea materna; es su madre doña Josefa Noti y Morales quien le trasmite el apellido. Tanto la certificación de fray Francisco Montoya como la del presbítero Gabriel Joseph Chacón hacen referencia explícita al parentesco de doña Josefa con don Pedro Noti.

Fray Francisco Ximénez (libro II) y fray Antonio de Remesal (libro VI, libro VII, cap. XXI-IX, libro VIII, cap. XI-XII) relatan algunos de los primeros momentos de los recién llegados dominicos y de sus enfrentamientos con los encomenderos y autoridades civiles españolas de la Provincia, en particular los causados por la postura del obispo Bartolomé de Las Casas. Buena parte de la información consagrada en ambas obras procede del diario de fray Tomás de la Torre, uno de los acompañantes del Obispo, de ahí la importancia de su relación, pues fue testigo presencial de varios de los acontecimientos relatados u obtuvo los datos de primera mano, de otros de sus compañeros de orden. Y trató personalmente con don Pedro, quien era el cacique del pueblo a la llegada de los dominicos.

En el recibimiento de los indios del pueblo de Chiapa, organizado por su encomendero Baltasar Guerra y descrito por fray Tomás de la Torre, podemos leer:

"Gran rato antes que llegasen al lugar de Chiapa salió todo el pueblo a recibirlos de esta manera: Venían adelante infinitos muchachos todos juntos y muchos mancebos con ellos, [...]. Tras esto vino a caballo el español, a quien sirven en este pueblo (Baltasar Guerra) venían con él a caballo el cacique que llaman don Pedro, indio bien grave y al parecer honrado, hombre de cincuenta años, de quien se ha de hacer adelante mención, y también venía a caballo otro indio llamado don Juan muy principal de aquel pueblo en linaje y en hacienda [Ximénez, libro II, cap. XLIV, p. 377]. 
Durante los primeros días de su estancia en el pueblo de Chiapa, Baltasar Guerra mantuvo engañados a los frailes, manifestando su afecto a la orden dominica en general y mostrándose satisfecho de su presencia, haciéndoles notar que estaba en desacuerdo con el comportamiento de los otros encomenderos de la Provincia, informándoles acerca de las injusticias y abusos que cometían, de la manera como hacían esclavos a los indios. Todo esto lo hizo con tal fervor que convenció a los misioneros de su veracidad, de tal manera que éstos escribieron memoriales a su favor, sin embargo, esta relación idílica pronto terminaría. Pero antes de que esto sucediera, fray Bartolomé de Las Casas quiso conocer el pueblo que daba nombre a su obispado, a él fue acompañado de varios frailes, entre ellos fray Pedro Calvo. El lujo del recibimiento al obispo fue tal que reproduzco aquí un fragmento:

"salieron nueve cruces, de rosas, plumas adornadas, bien galanamente: estuvieron los indios sentados en procesión al sol desque amaneció hasta las nueve sin menearse de allí: salieron todos los hijos de los principales vestidos de librea, adornados con piezas de oro con una danza de arcos y una canción en romance que el españoles había dado; y los principales iban como ya la pascua nos habían ido a ver a la ciudad con collares de oro hechos a su modo, otros con culebras, otros con tortugas de oro al cuello, que era cosa de ver; don Pedro llevaba tres collares de oro muy anchos que lo tomaban casi desde la cinta hasta la garganta. Llevaban estos muy galanas mantas de algodón blancas con muchas labores y plumas y sus camisas labradas y zaragülles y el calzado que, ya arriba dije que en ellos, es este muy lindo y hermoso" [Ximénez, libro II, cap. XLV, p. 380-381].
De la misma manera que a los frailes, Baltasar Guerra engatusó al obispo Las Casas, a tal grado lo convenció de sus virtudes y bondades que el prelado se deshacía en alabanzas para él, llegando incluso a escribir a su favor a España.

Entre los frailes que quedaron asignados al pueblo de Chiapa estaba Pedro Calvo. Este puso tal dedicación en aprender la lengua chiapaneca que, a decir de los cronistas dominicos:

“casi se olvidaba de sí, en la mesa y en el coro se estaba como pasmado: y así la supo tan en breve que parece increíble, antes de un mes, a los veinte días, predicaba ya y doctrinaba la gente y en tres meses la supo tan perfectamente que los indios estaban espantados, y así era él que trataba de la doctrina" [Ximénez, libro II, cap. XLVII, p. 386].

Las habilidades de fray Pedro Calvo se volcaron hacia sus hermanos de orden y otros empezaron a aprender la lengua. La elaboración de artes (gramáticas) y vocabularios de las lenguas indígenas fue una de las estrategias de evangelización y de penetración que las órdenes religiosas llevaron a cabo con notable éxito, que tal tarea fue hecha a conciencia podemos apreciarla en la gran cantidad de estos escritos que fueron publicados, aunque para las lenguas habladas en la Provincia de Chiapa apenas recientemente hemos tenido acceso a ellas, gracias a labor de Mario Humberto Ruz (1985,1986, 1989, 1997, en prensa). Si bien su objetivo principal era la prédica del cristianismo - para ello elaboraron doctrinas, confesionarios y sermonarios, entre otros escritos doctrinales - , pronto descubrieron que el manejo de las diversas lenguas indias les proporcionaba también una forma de poder frente a las autoridades españolas que, generalmente, tenían que recurrir a intérpretes para comunicarse con las pobla- 
ciones nativas. El uso de intérpretes podía ser un arma de doble filo, bien porque éstos fueran aliados de un grupo o de otro y en las traducciones mostraran su lealtad hacia alguno, bien porque fueran sobornados para distorsionar las declaraciones o la información que se les pedía traducir. Ejemplo de un intérprete cohechado por los españoles es el que participó en los testimonios levantados en contra del cacique don Pedro, como relatan Ximénez y Remesal.

Sin duda, gracias a las habilidades lingüísticas de fray Pedro Calvo, los engaños con que Baltasar Guerra había logrado el apoyo de los dominicos y del obispo Las Casas, fueron puestos al descubierto. El manejo de las lenguas nativas, en este caso de la chiapaneca, por los frailes, permitió la comunicación directa con los nuevos feligreses, que poco a poco fueron mostrando a los frailes quién era en realidad su encomendero y la clase de abusos y los excesos que había cometido con sus encomendados. Al principio, los misioneros dudaron de los dichos de los indios, sin embargo, poco a poco fueron poniendo pruebas a Guerra para desenmascararlo y ello dio lugar, por un lado, a que los dominicos se mostraran más enérgicos con él y tomaran decididamente el partido de los indios; por otro lado, permitió a los chiapanecas aliarse con los frailes en contra de su encomendero y otras autoridades civiles provinciales. Ello dio lugar a que el cacique don Pedro Noti se manifestara abiertamente a favor de los frailes e hiciera de su conocimiento los temores de su pueblo, a pesar de los cuales decidieron aliarse a éstos y enfrentar a Baltasar Guerra, quien urdió junto con las autoridades de Ciudad Real la forma de quitar del medio al cacique don Pedro y a aquellos otros que, a partir de las enseñanzas de los frailes, se estaban rebelando contra sus encomenderos. De tal manera que ante una comisión de chiapanecas enviada a Ciudad Real a hablar con Guerra, para de- cirle que era decisión del pueblo que los frailes se quedaran en él, es importante reproducir una parte del diálogo que se llevó a cabo entre Guerra y la comisión chiapaneca:

"ya vosotros sabéis como sois de buen linaje y como Don Pedro yo lo hice cacique y no fue hecho derechamente cacique (desmintiéndose el pobre con lo que con su boca había infinitamente afirmado). Tratad, dice, hijos míos, como me quitéis a este perro del cargo que yo os ayudaré. A los otros parecióles cosa larga y dijeron que aquel era su señor y que todo el puebló lo eligió, que ellos eran mozos para tratar de aquello" [Ximénez, libro II, cap. LI, p. 406].

El diálogo es significativo porque el encomendero afirma que él había designado cacique a don Pedro y alude a que esto no había sido de manera legal, cuestión que no debe extrañarnos y que fue frecuente en esos tiempos; sin embargo, la respuesta de los indios es interesante, deja ver que si bien don Pedro recibió el título de cacique de las autoridades, esto se debió a una elección del pueblo. Aquí conviene destacar lo que fray Francisco Ximénez asienta en otra parte de su obra: don Pedro Noti había sido designado cacique "a manera de elección canónica”. Esto significa que el cacique fue electo por su comunidad, después de que él había aceptado ser propuesto al cargo, y que la elección había sido confirmada por la autoridad competente.

El conflicto entre los encomenderos y autoridades provinciales en contra de los frailes dominicos continuó, los primeros no podían aceptar la postura de fray Bartolomé de Las Casas y sus seguidores, que atentaban en contra de sus privilegios, y la batalla se entabló tratando de ejercer el control de la población india. En la memoria de ésta se conser- 
vaba el recuerdo de todos los abusos y excesos cometidos por los conquistadores y sus encomenderos, ello se refleja en las palabras de don Juan, un indio principal de Chiapa que, tratando de disuadir a otros de su mismo pueblo del enfrentamiento con los españoles y aceptando la orden de Guerra de expulsar a los dominicos del pueblo, dijo a don Pedro Noti:

“¡Padre!, no te enojes conmigo por lo que te diré: ya sabes que este cristiano destruyó a Chiapa y la acabó y ahora es nada; éste quemó nuestros padres y nuestros viejos ¿cómo quieres que ahora lo neguemos?, ¿quieres que nos destruya otra vez?” [Ximénez, libro II, cap. LI, p. 406].

Baltasar Guerra recurrió al Cabildo de Ciudad Real y los alcaldes mandaron llamar al cacique don Pedro Noti para interrogarle acerca del comportamiento de los frailes; al defenderlos éste, lo amenazaron con la cárcel y la picota y al no quebrar su voluntad, posteriormente apresaron a varios hijos de los principales de Chiapa. Para atemorizar a toda la población india, el Cabildo de la ciudad sometió a interrogatorio a los caciques y principales de Zinacantán, quienes también defendieron a los religiosos.

Habiendo fracaso en su intento de echar a los dominicos de Chiapa y estando Baltasar Guerra preparando su viaje a España, éste trató de congratularse con ellos antes de partir, sin embargo, se negaron a recibirlo en confesión como tenía ordenado el Obispo. Cuando Guerra se fue a España, dejó en su lugar como encomendero a su hijo bastardo Juan Guerra, sobornando a los jueces logró que se le extendiera el nombramiento. Esto no fue aceptado por la Corona; y quitándolo del cargo, el pueblo de Chiapa quedó sin encomendero y desde entonces se llamó Chiapa de la Real Corona, es decir, su ad- ministración dependía de los funcionarios reales. Pero con esto no concluyeron los conflictos, y el cacique don Pedro siguió jugando un papel importante al lado de los dominicos en su lucha por la reducción de tributos y la aplicación de las Leyes Nuevas.

Finalmente, don Pedro fue encarcelado junto con otros caciques y principales. A don Pedro se le procesó de manera ilegal. Buscando testigos falsos, esto se hizo de la manera más sencilla: cohechando al intérprete que les decía que sólo movieran los labios y él diría lo que convenía, por ello se le destituyó como cacique de Chiapa; lo sentenciaron a pagar las costas del proceso y a seis meses de destierro de su pueblo, y en su lugar nombraron cacique a don Juan, quien estaba a favor de las autoridades de la ciudad y en contra de los dominicos. Terminado el destierro, don Pedro volvió a Chiapa y los frailes escribieron al obispo Las Casas, quien se encontraba en México a punto de partir para España para que intervinieran en el asunto de la destitución de don Pedro ante el Consejo de Indias.

Poco después murió el cacique don Juan, despedazado por su caballo y los españoles acusaron a don Pedro de haberle hecho maleficio, razón por la cual lo volvieron a encarcelar durante cinco meses. Los españoles nombraron como nuevo cacique a Hernando Noyola, individuo favorable a sus intereses y dispuesto a obedecer sus órdenes.

Gracias a los trámites realizados por el obispo Las Casas en España, la Corona envió a Diego Ramírez como juez visitador a Ciudad Real, quien llegó en 1548, para investigar acerca del maltratamiento dado a los dominicos y acerca de la destitución de don Pedro de su cacicazgo. Ramírez restituyó a don Pedro como cacique, y le entregó una cédula real a su favor (Ximénez, libro II, cap. LXXI, p. 498-499). El mismo juez traía otra real cédula dirigida a las autoridades de la provincia en 
la que se prohibia el quitar y poner caciques a voluntad de los encomenderos de los pueblos.

Sobre la importancia del cacique don Pedro Noti es interesante destacar lo que el presbítero Chacón asienta en la certificación que le extendió a don Domingo Santa María; dice que siendo cura interino del pueblo de Acala, vio unos títulos antiguos que estaban en manos del cacique de ese pueblo, don Manuel de Luna, en donde constaba que don Pedro había sido fundador del pueblo de Acala. Cabría preguntarse si esto fue cierto. En el mismo escrito, Chacón afirma que don Pedro "fue uno de los más principales conquistadores del expresado pueblo" de Chiapa; tal parece que se refiriera a su colaboración con los dominicos en la conquista espiritual y no en términos militares. Remesal copió una de las cédulas reales dirigida al cacique que a la letra dice:

EL PRINCIPE. Don Pedro cacique del pueblo de Chiapa, del obispado de Ciudad Real. Por relación de don fray Bartolomé de las Casas, obispo de ese obispado, he sido informado lo que habéis trabajado en ayudar a los religiosos de la Orden de Santo Domingo, para que los indios de ese pueblo y provincia sean instruidos y enseñados en las cosas de nuestra santa fe católica, y el favor y ayuda que para ello habéis dado. Lo cual os agradezco y tengo en servicio, y así os encargo y mando lo continuéis, hasta que del todo los naturales de esa provincia vengan a conocimiento de nuestra santa fe católica, que de lo que en ello habéis servido y sirviéredes, yo mandaré tener memoria, para vos hacer la merced que hobiere lugar.

$\mathrm{Y}$ ansí mismo he sido informado del dicho Obispo de las vejaciones, molestias, que los españoles os han hecho a causa de haber ayudado a los dichos religiosos en lo susodicho, y que por ello y por otras cosas que se os impusieron, un alcalde ordinario de esa ciudad de Ciudad Real de Chiapa os privó de vuestro cacicazgo, e vos puso otras penas, sobre lo cual yo he mandado brevemente se os haga justicia, y así se hará de manera que vos sea de desagravio del daño que habéis recibido, como allá veréis. Fecha en Monzón a veinte y dos días del mes de julio de mil y quinientos y cuarenta y siete años. Yo el Principe. Por mandado de su Alteza. Francisco de Ledesma [Remesal, libro VIII, cap. XI, pp. 131].

En relación con dos de los apellidos de don Domingo Santa María, Remesal afirma que a los descendientes de don Pedro Noti, fray Pedro de Barrientos les cambió el apellido Noti (lechuza) por el de Azebedo y fueron éstos quienes le dieron la cédula anterior. El apellido Guerra, el mismo del encomendero, al parecer fue adoptado, puesto que Baltasar Guerra y don Pedro eran compadres; el encomendero fue padrino de bautismo de un hijo del cacique [Remesal, Libro VI, cap. XXI, pp. 472].

\section{Bibliografía}

Ara, Domingo de, 1986, Vocabulario de lengua tzeeldal según el orden de Copanabastla, Edición de Mario Humberto Ruz, Universidad Nacional Autónoma de México, Instituto de Investigaciones Filológicas, Centro de Estudios Mayas, México. Carrasco, Pedro, 1982, Sobre los indios de Guatemala, Ministerio de Educación, Seminario de Integración Social Guatemalteca Núm. 42, Editorial José de Pineda Ibarra, Guatemala.

Farriss, Nancy M., 1992, La sociedad maya bajo el dominio colonial. La empresa colectiva de la supervivencia, Alianza América, Núm. 29, Alianza Editorial, Madrid.

Lenkersdorf, Gudrun, 2001, Repúblicas de Indios. Pueblos mayas en Chiapas, Siglo XVI, Universidad Nacional Autónoma de México, Instituto de Investigaciones Filológicas, Centro de Estudios Mayas, México.

Quezada, Sergio, 1993, Pueblos y caciques yucatecos, 1550-1580, El Colegio de México, México.

Remesal, Antonio de, 1964, Historia General de las Indias Occidentales y particular de la Gobernación de Chiapa y Guatemala, 
Ediciones Atlas, Biblioteca de Autores Españoles, vols. CLXXV y CLXXXIX, Madrid.

Ruz, Mario Humberto, (Edición y paleografía) 1989, Las lenguas del Chiapas colonial. Manuscritos en la Biblioteca Nacional de París. Volumen 1: Lenguas mayenses, Universidad Nacional Autónoma de México, Instituto de Investigaciones Filológicas, Centro de Estudios Mayas-Universidad Autónoma de Chiapas, Centro de Estudios Indígenas, México.

-, (Edición y paleografía) 1997, Las lenguas del Chiapas colonial. Manuscritos de la Biblioteca Nacional de París. Volumen 2: Lengua zoque, Universidad Nacional Autónoma de México, Instituto de Investigaciones Filológicas, Seminario de Lenguas Indígenas, México.

—, 1995, "Desfiguro de naturaleza: Los nobles de Ocozocoautla y los laboríos del valle de Xiquipilas en 1741", Anales de Antropología, Universidad Nacional Autónoma de Chiapas, Instituto de Investigaciones Antropológicas, vol. 29 (1992), México, pp. 397-436.

—, 1994, Un rostro encubierto. Los indios del Tabasco colonial, Centro de Investigaciones y Estudios Superiores en Antropología Social-Instituto Nacional Indigenista, Col. Historia de los pueblos indígenas de México, México.

—, y Dolores Aramoni, 1985, "Los anexos de fray Antonio de Aguilar, al diccionario tzeltal de Ara”, Revista de la UNACH 2, pp. 39-81, Tuxtla Gutiérrez, Chiapas.

Vos, Jan de, 1994, Vivir en frontera. La experiencia de los indios de Chiapas, Centro de Investigaciones y Estudios Superiores en Antropología Social-Instituto Nacional Indigenista, Col. Historia de los pueblos indígenas de México, México.

Ximénez, Francisco, 1977, Historia de la Provincia de San Vicente de Chiapa y Guatemala de la Orden de Predicadores, libros I y II, Sociedad de Geografía e Historia de Guatemala, Biblioteca Goathemala, vol. xxvIII, Guatemala.

\section{Documento}

Año de 1772. Información que comprueba el cacicazgo y distinguida prosapia de don Domingo Santa María Noti Quiñónez Guerra y Morales, Cometida su recepción al padre cura del pueblo de Chiapa de la Real Corona, por el señor licenciado don Joseph Suárez y Vega, juez provisor, gobernador y vicario general de este obispado. Curia diocesana.

[1r] Señor provisor y vicario general.

El cacique de Santo Domingo de Chiapa de la Real Corona, don Domingo Noti Quiñónez y Guerra, ante vuestra señoría digo: que a mi derecho conviene suplicar a vuestra señoría se sirva, interponiendo su judicial precepto, mandar por su decreto libre receptoría en forma jurídica cometida al venerable señor cura de esta Real Corona de Chiapa, a fin de que los naturales y vecinos declaren bajo la solemnidad del juramento, tomando de información de ellos en la manera siguiente:

Lo primero, si soy oriundo de esta sobredicha Real Corona, cacique, hijo legítimo de don Vicente Quiñónez y Guerra y de doña Josepha Notti y Morales, asimismo nativos de dicho territorio.

Iten. Juren y declaren, en la misma forma, si mis ascendientes por su genealogía, limpieza y pureza han ejercitado siempre, y obtenido, los empleos más honoríficos que se han dado y dan en dicha Real Corona, y si éstos se acostumbran dar con distinción a los caciques y no a otros.

Iten. Si saben si mis ascendientes han caído o [1v] perpetrado en alguna infamia, y si por esto han sido castigados. Últimamente, juren y declaren, si mi vida y costumbres, en el tiempo en que me han conocido, ha sido extraviada, relajada y fuera de la política cristiana, y por esto haya sido informado. Todo lo cual

A vuestra señoría, pido y suplico rendidamente se sirva proveer y mandar por ser de justicia, en que recibiré merced. Juro no proceder de malicia y en lo necesario, etcétera.

Domingo Santa María Noti Quiñónez y Guerra. 
Como lo pide y en su vista, damos comisión al padre cura de Chiapa, para que nombre notario o actuando ante sí, con testigos de asistencia, bajo la religión del juramento, examine a los testigos necesarios por el interrogatorio que en pedimento se contiene [2r] y evacuada que sea la información, nos la remitirá original, para proveerlo que convenga y sirva este decreto comisionario en forma. Así, su señoría, el señor licenciado don Joseph Zuáres de Vega, déan de esta santa iglesia catedral, juez provisor, gobernador y vicario general de este obispado, etcétera, lo proveyó, mandó y firmó a ocho días del mes de febrero de mil setecientos setenta y dos años. Doy fe.

Joseph Suárez de Vega.

Ante mí

Mariano Joseph Romeo

Notario Público

Chiapa, en veinte y cinco días del mes de mayo del año de mil setecientos y setenta y dos. Yo fray Juan de Abadía del Orden de Predicadores, cura interino de este pueblo de Chiapa y Suchiapa, habiendo recibido la comisión que antecede: la obedecí, y para darle entero cumplimiento, nombre por notario a don Joseph Gatica, quien admitió el cargo, y porque conste lo firmó conmigo en este dicho pueblo, día, mes y año dicho.

\section{Joseph Gatica}

Fray Juan de Abadía Cura y comisionado

En virtud de la comisión que antecede, hice comparecer ante mí a don Bisente Balbuena, cacique, primer testigo; y habiéndole tomado juramento, que hizo, por Dios y una señal de su santa cruz, de decir verdad, dijo a la primera pregunta del interrogatorio inserto en la petición: que sí: el dicho don Domingo de Santa María Quiñónez y Guerra Noti y Morales, era oriundo de este pueblo de Chiapa, cacique, hijo legítimo de don Bisente Quiñónez Guerra y doña Josepha Noti y Morales; asimismo, y que éstos también eran oriundos de este dicho pueblo.
A la segunda pregunta del citado interrogatorio: que sí, sus ascendientes habían ejercitado y obtenido los empleos más honoríficos que se dan a los [3r] caciques. Y respondió del mismo modo diciendo: que sus ascendientes habían sido, los más, alcaldes de primer voto y gobernadores de este dicho pueblo.

A la tercera: que si sus ascendientes habían caído en alguna infamia y por eso habían sido castigados, respondió del mismo modo, diciendo: que nunca había visto ni oído decir, que sus ascendientes fuesen infames y por esto castigados.

A la cuarta y última pregunta: que si dicho don Domingo de Santa María Quiñónez y Guerra Noti Morales, había sido de mala vida y costumbres, respondió del mismo modo, diciendo que siempre lo había conocido de buena vida y costumbres, sin haber dado escándalo alguno. Y habiendo sido leída esta su declaración por el presente notario se ratificó en ella. Dijo que no firmaba por no saber escribir, y por ser todo verdad [3v] lo firmé con el notario nombrado en este dicho pueblo, en dicho día, mes y año.

Fray Juan de Abadía

Cura y comisionado

Joseph Solís de Gatica

Notario nombrado

En prosecución de las diligencias que por comisión estoy practicando, compareció ante mí, hoy día de la fecha, don Lucas de Morales, cacique principal de este dicho pueblo y segundo testigo, y habiendo hecho juramento, a Dios y una señal de su santa cruz, de decir verdad en todo lo que fuere preguntado. Respondió a la primera pregunta del interrogatorio inserto en la petición: que si el referido don Domingo de Santa María Quiñónez y Guerra Noti y Morales era oriundo de este pueblo de Chiapa y cacique, hijo legítimo de don Bisente Quiñónez y Guerra y de doña Josepha Noti y Morales, y que si éstos eran también oriundos de este [4r] dicho pueblo; respondió, jurando a Dios y a una cruz, diciendo: que el referido era oriundo de este pueblo y cacique legítimo de padre y madre, los referidos don Bisente Quiñónez y Gue- 
rra y doña Josepha Noti y Morales, los que también eran oriundos de este dicho pueblo.

A la segunda pregunta: que si sus ascendientes habían ejercitado y obtenido los empleos más honoríficos que se daban a los caciques, respondió en la misma forma, diciendo: que conoció a don Antonio Quiñónez y Guerra, tío del referido don Domingo, etcétera, que fue alcalde de primer voto y gobernador de este dicho pueblo, y que el padre del referido don Domingo Santa María, etcétera, don Bisente Quiñónez y Guerra, fue alcalde de primer voto, y asimismo, ha oído decir que los más de sus ascendientes han ejercitado y obtenido todos los empleos más honoríficos de los caciques de este dicho pueblo.

[4v] A la tercera: si los ascendientes fueron infames y castigados por algún escándalos, respondió que, conoció a don Bisente Guerra y Quiñónez, tío del referido, y a otros parientes del referido, y que había oído decir que todos los ascendientes nunca habían caído en infamia alguna, ni habían sido castigados.

A la cuarta y última pregunta: que si don Domingo había vivido mal acostumbrado y con alguna mala fama: respondió del modo de arriba: que siempre lo había visto vivir bien, honrado y sin escándalo alguno; y habiéndole leído esta declaración por el dicho notario, se ratificó, dijo no sabía escribir, y por ser verdad todo, lo firmé con el notario nombrado en este dicho pueblo, en dicho día, mes y año.

Fray Juan de Abadía

Cura comisionado

Ante mí

Joseph Gatica

Notario nombrado

En conclusión de la información referida, [5r] compareció ante mí don Andrés Guzmán, cacique principal y último testigo; y habiendo hecho juramento por Dios y una señal de su santa cruz de decir verdad, dijo a la primera pregunta del citado interrogatorio: que sí, el referido don Domingo de Santa María, etcétera, era oriundo de esta Real Corona, cacique, hijo legítimo de don Bisente Quiñónez y Guerra y doña Josepha Noti y Morales, nativos también de dicho territorio; respondió que el referido don Domingo de Santa María, etcétera, era nativo de esta Real Corona, cacique, hijo legítimo de don Bisente Quiñónez y Guerra y de doña Josepha Noti y Morales, también nativos de este dicho pueblo.

A la segunda: que si sus ascendientes, por su limpieza y pureza, han ejercitado y obtenido los empleos más honoríficos que se dan a los caciques y no a otros. Respondió que los más de sus [5v] ascendientes que había conocido, habían sido alcaldes de primer voto y gobernadores de esta dicha Real Corona.

A la tercera: que si sus ascendientes habían caído y perpretado alguna infamia y por esto habían sido castigados: respondió que no, antes si, habían sido honrados.

A la cuarta y última pregunta: que si la vida y costumbres del referido don Domingo Santa María, etcétera, en el tiempo que lo ha conocido, han sido extraviadas o relajadas y fuera de la política cristiana y si por esto ha sido infamado; respondió que no, porque siempre lo ha visto vivir en juicio y honrado; habiéndole sido leída esta su declaración por el presente notario, se ratificó en ella, dijo no firmaba por no saber escribir, y por ser todo verdad lo firmé con el notario nombrado, en este pueblo de Chiapa, en veinte y seis días del mes de mayo del año [6r] de mil setecientos y setenta y dos.

Fray Juan de Abadía

Cura y comisionado

Ante mí

Joseph Solís Gatica

Notario nombrado

En este dicho pueblo de Chiapa, en dicho día, mes y año, concluida esta información en seis fojas útiles, se remite original al señor licenciado don Joseph Suárez de Bega, déan de la santa iglesia catedral, juez provisor, gobernador y vica- 
rio general de este obispado, etcétera, como ordena en su auto de ocho de febrero de dicho año, y para que conste lo firmé con el presente notario en este dicho pueblo, en dicho día, mes y año.

Fray Juan de Abadía

Cura comisionado

Ante mí

Joseph Solís Gatica

Notario nombrado

[7r] Fray Francisco Montoya de el sagrado Orden de Predicadores y conventual en el convento de este pueblo del señor Santo Domingo de Chiapa de la Real Corona.

Certifico en la mejor forma que puedo y debo, con licencia de mi prelado, a petición de don Domingo Guerra,, sobre que le de certificación de sangre y parientes, y digo que, a dicho don Domingo conozco de más de veinte y cinco años, y asimismo a sus padres y parientes. $Y$ ser el dicho don Domingo cacique por ambos lados, conocido y de los más distinguidos en este pueblo de Chiapa, que siempre han ocupado los mejores puestos y oficios en este dicho pueblo, que no son permitidos a otros que no sean caciques. Don Vicente Guerra se llamó el padre de dicho don Domingo, el cual fue alcalde de primer voto en este dicho pueblo. Conocí también a don Antonio y a don Nicolás Guerra, hermanos de padre y madre del dicho don Visente y tíos del dicho don Domingo. Don Nicolás fue alcalde de primer voto, como también lo fue don Antonio, y éste también gobernador en este pueblo. La madre de dicho don Domingo, y mujer del dicho don Visente se llama doña Josepha Noti y Morales cuales dos apellidos [ilegible por humedad] [no] [7v] bles y estimados de este pueblo de Chiapa, porque don Pedro Noti, antiguo cacique y el más señalado de aquel tiempo en servicio de ambas majestades, desciende la dicha doña Josepha. Por parte de Morales es asimismo, cacica, que por la presente viven varios, que todos han ocupado los primeros puestos en este pueblo, de alcaldes de primer voto y de regidores mayores, que como dije, nunca los indios dan, ni permiten dar, a ninguno que no sea cacique. $Y$ en fin, en este pueblo es público y notorio la distinción de los dichos tres apellidos Noti, Guerra y Morales; y no hay duda en que el dicho don Domingo, de todos los tres desciende, y que es por la presente de la nobleza más apreciable entre ellos en este pueblo de Chiapa. Y a todo esto se agrega el haber sido los dichos, buenos cristianos y leales vasallos de su majestad, especialmente el dicho don Domingo, quien desde que lo conozco no ha dado que decir en mala nota de su persona. Todo lo cual por constarme ser así, y haberlo conocido, como digo más de veinte y cinco años, lo certifico y juro in verbo sacerdotis tacto pectore, ser del todo cierto cuanto tengo dicho en esta certificación. [8r] Y ratificándome en el juramento, lo firmé en este pueblo de Chiapa de la Real Corona, en veinte y seis días del mes de mayo de mil setecientos setenta y uno.

\section{Fray Francisco Montoya}

[9r] Don Gabriel Joseph Chacón de la Peña, clérigo presbítero, y residente en Ciudad Real, certifico en la más bastante forma que debo y puedo; como conozco, hace más de veinte y seis años, al cacique don Domingo Guerra Morales y Noti, hijo legítimo de don Visente Guerra y Quiñónez y de doña Josepha Noti y Morales, vecinos y naturales del pueblo de Chiapa de Indios de la Real Corona, principales caciques y de los más distinguidos de dicho pueblo. Y el citado don Visente Guerra y Quiñónez, padre legítimo de dicho don Domingo, conocí muy bien, y oí decir que había ejercido el oficio de alcalde ordinario de primer voto en dicho pueblo, cuyo título y honor sólo ejercen los caciques distinguidos, limpios y cristianos, por estar establecido así entre ellos; y cuando conocí al citado don Visente Guerra y Quiñónez, carecía totalmente de vista, por cuyo motivo su continuo y cristiano ejercicio era el de enseñar la doctrina cristiana, así a los niños de los naturales del pueblo en su idioma como a los hijos de los españoles más distinguidos, y el de servir a la Iglesia de músico, por cuyo motivo es de la mayor estimación, así de los reverendos padres del sagrado Orden de Predicadores del convento del citado pueblo y demás vecinos y el tiempo que ha que conozco a el dicho cacique [don] Domingo que habrá más de veinte y seis años [9v] y no me consta y menos oído decir cosa alguna que deslustre su ca- 
lidad y limpieza, antes sí, he reconocido ser un mozo de toda honra y virtud, ejercitándose a causa de us cortas facultades en servir a eclesiásticos distinguidos, para poder alimentar, socorrer y vestir a sus ancianos padres y hermanas, y a su legítima madre doña Josepha Morales y Noti, quien en la actualidad vive, conozco, me consta y he oído decir, desciende no solamente d los caciques más principales, limpios y cristianos, sino también del cacique mayor don Pedro Noti, quien fue uno de los más principales conquistadores del expresado pueblo; y siendo cura interino del pueblo de Acala, ocho leguas inmediato al de la Real Corona, supe por unos títulos que existen en poder de uno de los caciques de dicho pueblo de Acala, llamado don Manuel de Luna, que el citado cacique mayor don Pedro Noti, había sido fundador del mencionado Acala, y llegado a noticias de su majestad dicha fundación, se digno darle las gracias con el renombre de fundador, nominándole con el título y honor y grandeza de príncipe, confiriéndole ciertos méritos a él y a toda su parentela, como consta de los citados títulos. Más, conocí a don Antonio Guerra y Quiñónez, hermano carnal de padre y madre de don Visente Guerra y Quiñónez, con el oficio y honor de gobernador del supradicho pueblo, cuyo oficio sólo obtienen los principales caciques, y no otra clase de personas. Doy éste, a pedimento del cacique don Domingo Guerra Noti y Morales, [10r] para los efectos que convenirle puedan; y por ser verdad lo juro in verbo sacerdotis tacto pectore, y ratificándome en todo, lo firmó en Ciudad Real de Chiapa, en cinco días del mes de junio del año de mil setecientos setenta y dos.

Gabriel Joseph Chacón de la Peña

[11r] Fray Thomas de Loaysa y Coronado del sagrado Orden de Predicadores, cura por su majestad (que Dios guarde) de el pueblo de Ystacomitán y sus anexos, superior de el convento de nuestro padre Santo Domingo de Chiapa, con licencia de mi prelado, etcétera.

Certifico en la mejor forma que puedo y debo, como don Domingo Guerra es hijo legítimo de don Vizente Guerra Quiñónez y de doña Josepha Noti y Morales: indios principales, caciques de este pueblo, descendientes de los más dis- tinguidos de ellos. A su propio padre conocí de alcalde ordinario y a su hermano don Vizente, que se nombraba don Antonio Guerra Quiñónez, le conocí en el propio oficio, y ascendió a gobernador. Oficios que obtienen otra clase de personas que no sean descendientes de legítimos caciques. Por parte de la madre, la conozco por tal descendiente de cacique, y para mayor probabilidad de mi verdad, conocí a un hermano de la citada doña Josepha, que se llamaba don Andrés de morales, ejerciendo el oficio de alcalde ordinario, y en este y otros oficios en que sólo se ejercitan los principales caciques, he conocido a sus descendientes. Todo lo cual por ser verdad lo juro in verbo sacerdotis tacto pectore; y ratificándome en todo doy ésta a petición de la parte para los [11v] ocursos que convengan. En veinte y seis días del mes de mayo de mil setecientos y setenta y uno.

Fray Thomas de Loaysa y Coronado

[12r] Señor provisor y vicario general.

El cacique de Santo Domingo de Chiapa de la Real Corona, don Domingo noti Quiñónez y Guerra, por el recurso que haya lugar en derecho, ante vuestra señoría parezco y digo: que las diligencias que debidamente presento, se me entregaron por el juez comisionado. En cuya atención se sirva de aprobarlas, y que se me den los testimonios que necesitaré de ellas, como asimismo de las certificaciones que con la debida solemnidad presento, para que vuestra señoría las agregue a dichas diligencias, como justificantes de lo que solicito probar. Por tanto

A vuestra señoría suplico se sirva hacer como pido, que es justicia, juro en forma no ser de malicia y lo necesario, etcétera.

Domingo Santa María Noti Quiñónez y Guerra

En la Ciudad Real de Chiapa, a veinte y un días [12v] del mes de julio de mil setecientos setenta y dos años. El señor deán de esta santa iglesia catedral, licenciado don Joseph Suáres de Vega, juez provisor, gobernador y vicario general de este obispado, por el ilustrísimo y reverendísimo se- 
ñor maestro don fray Juan Manuel García de Vargas, obispo de esta diócesis, del consejo de su majestad, etcétera. Habiendo visto la información tomada por especial comisión que se le cometió al reverendo padre cura interino del partido de Chiapa, y las certificaciones nuevamente presentadas por el suplicante. Su señoría, el señor provisor, dijo que las aprobaba y aprobó en cuanto ha lugar por derecho, y daba y dio por bastante dicha información recibida en cuanto contiene para la certeza y justificación del cacicazgo del suplicante, por lo respectivo a este juzgado, y mandaba y mandó, se den los testimonios que se pidieren, autorizados en pública forma y manera que hagan fe, para cuya validación y firmeza interponía su autoridad y judicial decreto. Y por este auto así lo aprobó, proveyó, mandó y firmó.

Joseph Suárez de Vega

Ante mí

Joseph Mariano de Paz Notario público

Doy fe, en veinte y tres de julio de el [13r] año presente, ministrado en virtud de lo mandado en el auto de enfrente, dos testimonios a la parte de don Domingo Santa María Noti Quiñónez. Y para que conste lo rubriqué.

Rúbrica [Joseph Mariano de Paz] 